OPEN ACCESS

Edited by:

Eric Ghigo,

Centre National de la Recherche Scientifique (CNRS), France

Reviewed by: Xin Li,

Tufts University School of Medicine, United States

Oleg Y. Mediannikov, Institute of Research for Development,

France

${ }^{*}$ Correspondence:

Ana Domingos

adomingos@ihmt.unl.pt

Received: 12 June 2017 Accepted: 19 September 2017 Published: 29 September 2017

Citation:

Antunes S, Rosa C, Couto J, Ferrolho $J$ and Domingos A (2017)

Deciphering Babesia-Vector Interactions.

Front. Cell. Infect. Microbiol. 7:429. doi: 10.3389/fcimb.2017.00429

\section{Deciphering Babesia-Vector Interactions}

\author{
Sandra Antunes ${ }^{1}$, Catarina Rosa ${ }^{2}$, Joana Couto ${ }^{1}$, Joana Ferrolho ${ }^{1}$ and Ana Domingos ${ }^{1 *}$ \\ ${ }^{1}$ Global Health and Tropical Medicine, Instituto de Higiene e Medicina Tropical, Universidade Nova de Lisboa, Lisbon, \\ Portugal, ${ }^{2}$ Instituto de Higiene e Medicina Tropical, Universidade Nova de Lisboa, Lisbon, Portugal
}

Understanding host-pathogen-tick interactions remains a vitally important issue that might be better understood by basic research focused on each of the dyad interplays. Pathogens gain access to either the vector or host during tick feeding when ticks are confronted with strong hemostatic, inflammatory and immune responses. A prominent example of this is the Babesia spp. - tick-vertebrate host relationship. Babesia spp. are intraerythrocytic apicomplexan organisms spread worldwide, with a complex life cycle. The presence of transovarial transmission in almost all the Babesia species is the main difference between their life cycle and that of other piroplasmida. With more than 100 species described so far, Babesia are the second most commonly found blood parasite of mammals after trypanosomes. The prevalence of Babesia spp. infection is increasing worldwide and is currently classified as an emerging zoonosis. Babesia microti and Babesia divergens are the most frequent etiological agents associated with human babesiosis in North America and Europe, respectively. Although the Babesia-tick system has been extensively researched, the currently available prophylactic and control methods are not efficient, and chemotherapeutic treatment is limited. Studying the molecular changes induced by the presence of Babesia in the vector will not only elucidate the strategies used by the protozoa to overcome mechanical and immune barriers, but will also contribute toward the discovery of important tick molecules that have a role in vector capacity. This review provides an overview of the identified molecules involved in Babesia-tick interactions, with an emphasis on the fundamentally important ones for pathogen acquisition and transmission.

Keywords: tick-pathogen interaction, Babesia spp., vector, babesiosis, tick-borne diseases

\section{INTRODUCTION}

Parasites from the genus Babesia are responsible for causing an emerging zoonotic disease called babesiosis. Transmission occurs mainly through the bite of a Babesia-infected tick and, less commonly, by blood transfusion (Leiby, 2006; Ord and Lobo, 2015).

At least four Ixodidae genus are recognized as Babesia vectors: Rhipicephalus, Ixodes, Haemaphysalis, and Hyalomma (Sonenshine and Michael Roe, 2014). This disease has a considerable impact on the health and economy of the livestock industry, mainly in tropical and subtropical climates, with Rhipicephalus microplus and Rhipicephalus annulatus the main vectors of Babesia bovis and Babesia bigemina, the etiological agents of bovine babesiosis (Bock et al., 2004). In small ruminants, infections can be caused by several Babesia species, such as B. ovis, transmitted to sheep usually by the tick $R$. bursa 
(Shayan et al., 2007; Ranjbar-Bahadori et al., 2012; Ferrolho et al., 2016). Dogs are susceptible of infection by B. canis vogeli and B. gibsoni, primarily transmitted by R. sanguineus (SolanoGallego et al., 2016; Chao et al., 2017). Human babesiosis, caused largely by Babesia microti and Babesia divergens, is not acknowledged as a tropical neglected disease, but there is a growing concern globally regarding this emerging zoonosis (Ord and Lobo, 2015).

Despite the fact that Babesia infections tend to impair tick development, an adaptive tolerance to Babesia has been described in $R$. microplus suggesting a balance between tick defense mechanisms and tick-pathogen mutual interaction(s) (Cen-Aguilar et al., 1998; Chauvin et al., 2009; Florin-Christensen and Schnittger, 2009; Lack et al., 2012; Gou et al., 2013; de la Fuente et al., 2016).

The development of improved tick and tick-borne disease control measures are essential to overcome the lack of data regarding which tick molecules are important and how they may be suitable as study targets. Based on this, herein we will discuss the functional roles of several molecules involved during the infection of tick tissues by Babesia spp.

\section{TICK MIDGUT MOLECULES WITH A ROLE IN BABESIA ACQUISITION}

Once ingested Babesia-infected red-blood cells reach the tick midgut many parasites will be destroyed or degenerate, but a small number will evolve to gametocytes, essential for zygote fusion and penetration of the midgut peritrophic membrane (Sonenshine and Hynes, 2008; Chauvin et al., 2009; Maeda et al., 2017). Recently, it was proposed that during the Babesia spp. sexual phase, some specific proteins with known functional roles in recognition and adhesion are expressed, including glycosylphosphatidylinositol (GPI) anchored proteins that interact with specific targets in the epithelial cells (Bastos et al., 2013; Alzan et al., 2016).

In the R. microplus midgut, proteomic analysis has identified a mitochondrial voltage-dependent anion-selective channel (BmVDAC) polypeptide, also known as mitochondria porin that binds to $B$. bigemina sexual stage proteins (Mosqueda et al., 2004; Rodríguez-Hernández et al., 2012). VDAC was first described as located in the external mitochondrial membrane that regulates the flux of small molecules into the mitochondrial space membrane having a role in cell metabolism and apoptosis (Young et al., 2007). In mosquitoes, VDAC plays a role during Plasmodium sp. invasion of the midgut; likewise, the dissemination of $B$. burgdorferi through the tick midgut might be associated with the ability of VDAC to bind a tissue-type plasminogen activator (Coleman et al., 1997; Ghosh et al., 2011). Under Babesia invasion this protein was found over-represented in the R. microplus midgut (Rodríguez-Hernández et al., 2012).

The tick receptor of the outer surface protein A (TROSPA) was firstly identified in the I. scapularis midgut epithelium as a receptor for $B$. burgdorferi, suggesting it has the potential to control bacterial infections in ticks (Pal et al., 2004; Konnai et al., 2012; Urbanowicz et al., 2016). In R. annulatus, an orthologue of trospa gene was over-expressed during B. bigemina infection and gene knockdown significantly reduced $B$. bigemina infection levels by 70 and $83 \%$ in R. microplus and R. annulatus, respectively (Antunes et al., 2012). In addition, B. bigeminainfected cattle vaccinated with TROSPA revealed close to an $80 \%$ decrease in pathogen transmission to ticks (Merino et al., 2013). In $R$. annulatus, this receptor was found not only in the midgut, but also in the salivary glands (SGs) and ovaries (Antunes et al., 2014).

During protozoal invasion, the tick innate immune response leads to the rapid, synthesis of defensins and tick antimicrobial peptides (AMPs). These constitute an important humoral defense mechanism, which is also active against intracellular bacteria and fungi (Antunes et al., 2012; Hajdusek et al., 2013; Tonk et al., 2015). The midgut defensin-like protein, longicin, was first identified in the tick Haemaphysalis longicornis and has a role in Theileria equi proliferation (Tsuji et al., 2007). Merozoite in vitro cultures were inhibited in the presence of recombinant longicin while the inoculation of this protein led to a reduction of $B$. microti parasitaemia in infected mice. Also, longicin silencing led to an increase in B. gibsoni parasitaemia in several tick tissues, including midgut, ovaries and eggs. Accumulated data on the function of this protein indicate that longicin has a babesiacidal effect. Microplusin was the first fully characterized member of a family of cysteine-rich AMPs in R. microplus (Fogaça et al., 2004); in R. annulatus, was found over represented in response to B. bigemina infection (Antunes et al., 2012).

Other molecules present in the midgut that also protect the tick from pathogen invasion are the MD-2-related lipidrecognition (ML)-domain containing proteins related with lipid recognition (Rudenko et al., 2005), proteases and protease inhibitors (Sonenshine and Hynes, 2008; Kopacek et al., 2010; Antunes et al., 2012; Hajdusek et al., 2013). Longipain, a $H$. longicornis midgut cysteine protease, has shown similar effects to longicin. Recombinant longipain was also able to inhibit the proliferation of T. equi merozoites, and gene silencing resulted in an increase of protozoa in the midgut lumen, ovaries and hatched larvae (Tsuji et al., 2008). Also in H. longicornis, a leucine-rich repeat domain-containing protein (LRR) has been identified as over represented in all tick tissues, with the exception of the ovary, where it is constitutively expressed. In vitro, a specific recombinant LRR has demonstrated a growth inhibitory effect on B. gibsoni with similar or better results than traditional antibabesial drugs (Maeda et al., 2015).

Tick Kunitz-type protease inhibitors may restrict pathogen infection, presumably via the inhibition of microbial proteinases (Sasaki and Tanaka, 2008; Antunes et al., 2012). This group of genes was upregulated in response to infection (Antunes et al., 2012; Heekin et al., 2013), but its influence in Babesia acquisition was only related to ovary infection (Rachinsky et al., 2007; Bastos et al., 2009).

Bm86 is a glycoprotein, recognized for the first time in R. microplus, and present in midgut cells, that is likely to be involved in the endocytosis of the blood ingested by ticks (Gough and Kemp, 1993; Bastos et al., 2010; Rodríguez-Mallon, 2016). Regardless of the efficiency of Bm86 against tick infestation, some studies aimed to evaluate the role of Bm86 in Babesia 
infection (Bastos et al., 2010; Rodríguez-Mallon et al., 2013). RNA interference (RNAi) studies carried out in R. microplus females showed that $B m 86$ silencing significantly reduced the number of ticks; by contrast, silencing did not affect the efficiency of transovarial transmission of B. bovis (Bastos et al., 2010). In a different study using Gavac ${ }^{\circledR}$, a vaccine based on the Bm86 antigen, naïve nymphs that co-fed on immunized dogs presented lower levels of B. canis, (Rodríguez-Mallon et al., 2013). It is conceivable that the lysis of midgut cells inhibited the entry of zygotes and/or their posterior differentiation into motile ookinetes, compromising B. canis acquisition by the nymphs.

Subolesin, firstly identified in I. scapularis ticks as an orthologue of akirin in insects and vertebrates (Almazán et al., 2003; Galindo et al., 2009), is a highly conserved protein in eukaryotes, including many tick species (Moreno-Cid et al., 2013; Antunes et al., 2014), suggesting its potential as a candidate antigen for an anti-tick and tick-borne pathogen (TTBP) vaccine. Subolesin family proteins are transcriptional factors, regulating protein expression in cellular pathways involved in the response to pathogen infection (de la Fuente et al., 2013; Sultana et al., 2015). Subolesin silencing mediated by RNAi led to a lower B. bigemina infection in $R$. microplus (Merino et al., 2011) but, in contrast, in $R$. annulatus, silencing did not lead to a significant decrease in B. bigemina levels (Antunes et al., 2012). Vaccination using subolesin and a chimera containing subolesin protective epitopes (Q38) revealed an effect on B. bigemina transmission to feeding ticks (Merino et al., 2013). Subolesin expression and subolesin-mediated innate immunity varies according to the pathogen and tissue (Zivkovic et al., 2010), which explains the variation in the results. However, it seems that targeting subolesin by vaccination or its gene by RNAi would result in lower Babesia infection levels.

The tick midgut is one of the few major organs that defines vector competence since it is the first obstacle that several pathogens, including Babesia, have to cross. Still, our understanding of the interplay between an infective pathogen and the tick midgut continues to be poor and requires further studies to better define this important interaction.

\section{TICK HAEMOLYMPH AND OVARY MOLECULES ACTING IN BABESIA DISSEMINATION}

After the successful invasion of the midgut epithelium, Babesia zygotes go through meiosis and differentiate into motile ookinetes that go across the haemocoel, with the help of haemolymph; in the haemocoel, the parasite undergoes asexual reproduction, resulting in several sporokinetes spread for all tick organs throughout all tick life stages (transstadial transmission) (Schnittger et al., 2012).

When a tick experiences microbial invasion, for example from a protozoa like Babesia spp., the hemocytes increase their circulating number to destroy and control the invader, phagocytizing small particles and microbes (Inoue et al., 2001; Villar et al., 2015). Besides phagocytosis, other processes including nodulation and encapsulation, and molecules like
AMPs, lysozymes, proteases, protease inhibitors, and lectins, that exist in the haemolymph act directly on the pathogen (Esteves et al., 2008; Kotsyfakis et al., 2015). B. bigemina exhibits motility when reaching the haemolymph and adheres to $R$. microplus haemocyte membranes (de Rezende et al., 2015), however there is no information about how Babesia spp. invasion is controlled at the haemolymph level.

In female ticks, effective infection of ovaries and the eggs allow transovarial transmission of almost all Babesia species, a distinctive characteristic of this genus (Homer et al., 2000; Chauvin et al., 2009) that can be interpreted as an adaptation to efficiently persist in the ecosystem (Chauvin et al., 2009). The first ovarian proteomic profile of $R$. microplus infected with $B$. bovis identified a small number of differentially represented proteins. Among these proteins were calreticulin, glutamine synthetase and a family of Kunitz-type serine protease inhibitors; whereas between the less represented proteins were a tick lysozyme and a group of small proteins that may belong to a family of AMPs (Rachinsky et al., 2007). Ovarian genes involved in the stress response, detoxification and immune responses were found potentially regulated by $B$. bovis infection (Heekin et al., 2013); many of these genes translate into proteases and protease inhibitors that participate in the ovarian immune response. A putative immunophilin (Imnp) and a putative Kunitz-type serine protease inhibitor (Spi) genes were found to be up regulated when tick ovaries were infected (Rachinsky et al., 2007) and the Imnp knockdown revealed a significant increase of larval infection, suggesting that this molecule might control the protozoan invasion of tick ovaries, and subsequent larval progeny. Immunophilin proteins, also known as cyclophilins, are associated with multiple cellular processes, like protein folding, trafficking and defense mechanisms (Wang and Heitman, 2005), however their role(s) during Babesia infection is still unknown.

The $H$. longicornis vitellogenin receptor $(\mathrm{VgR})$ has been associated with the transovarial transmission of $B$. gibsoni. $V g R$ silencing results in the absence of $B$. gibsoni infection and development of abnormal eggs (Boldbaatar et al., 2008) confirming its influence on oogenesis acting on heme detoxification and egg maturation (Boldbaatar et al., 2010; Perner et al., 2016). These results may suggest that Babesia molecules have ligand-binding activity for tick $\mathrm{VgR}$, consequently invading the developing oocyte (Boldbaatar et al., 2008).

Ovarian proteins can affect tick biology by decreasing oogenesis and embryogenesis, which reduce tick reproduction rates and TBP transmission by blocking transovarial transmission, making these molecules promising targets for vaccine development.

\section{TICK SALIVARY GLAND MOLECULES THAT INTERVENE IN BABESIA TRANSMISSION}

When Babesia kinetes reach the SGs they undergo a final step of multiplication to produce sporozoites, the vertebrate hostinfective stage. SGs can be considered as the last barrier that 
parasites must overcome to complete their life cycle in the vector, facing similar obstacles to those of the midgut (Chauvin et al., 2009).

Different SGs transcriptomes, commonly referred to as sialomes, from soft and hard ticks have been published (Francischetti et al., 2008, 2011; Anatriello et al., 2010; Karim et al., 2011; Ribeiro et al., 2011; Garcia et al., 2014; Yu et al., 2015; de Castro et al., 2016), showing genes encoding AMPs, such as defensins, microplusin/hebraein, Kunitz domain-containing proteins, lipocalins, proteases and other molecules related to tick defense mechanisms. Despite their importance for transmission, reports describing the influence of SG molecules on Babesia infection are absent.

The sialome of the soft tick Ornithodoros parkeri contains a putative serum amyloid A protein, whose orthologue was also found in the I. scapularis genome. In vertebrates, this protein is involved in the acute phase of an inflammatory response (Francischetti et al., 2008; Antunes et al., 2012). Vertebrate serum amyloid A protein was found increased in cattle with more resistance to tick infections, suggesting its involvement in the stress response induced by tick infestations (Ferreira et al., 2004). The expression of a putative serum amyloid $A$ gene was increased in response to $B$. bigemina infection in $R$. annulatus and gene knockdown resulted in a reduction of 66 and $86 \%$ of the infection levels, in $R$. microplus and $R$. annulatus, respectively (Antunes et al., 2012).

Calreticulin, has been identified in tick ovaries, midgut and SGs (Antunes et al., 2012, 2015). The role of this molecule in ticks is still not clear but some studies support its presence in the SGs and saliva is presumably related to a mechanism to avoid vertebrate host defense responses (Jaworski et al., 1995; Ferreira et al., 2004; Antunes et al., 2015) and may lack the anti-thrombotic and complementinhibiting characteristics that suppress host defense actions (Kim et al., 2015). The gene encoding this protein was found to be over expressed in R. annulatus infected with B. bigemina. Calreticulin knockdown had a significant effect on pathogen infection in $R$. microplus, but not in $R$. annulatus ticks, affecting the body weight in both tick species (Antunes et al., 2012). According to this and to other reports, it is thought that calreticulin acts during blood feeding (Ferreira et al., 2002; Antunes et al., 2012) and may alter calcium metabolism during Babesia infection. Babesia sp. may need calcium ions to invade tick cells as shown for T.equi (previously classified as B. equi). A pilot immunization trial in cattle using recombinant calreticulin failed to reduce tick infestation, probably due to the low immunogenicity of the protein (Ferreira et al., 2002). More recently, serum with anti-calreticulin antibodies also failed to promote a significant decrease in B. bigemina infection in R. microplus (Antunes et al., 2015). In this study, calreticulin immunolocalization assays have shown that this molecule can be found in the tick midgut, ovaries and SGs, suggesting that it might have a role in Babesia infection in all these tissues.

Other molecules, such as TROSPA, already discussed, have been also identified in tick SGs, where it may function as a receptor for Babesia parasites. Tick SG proteins are of extreme

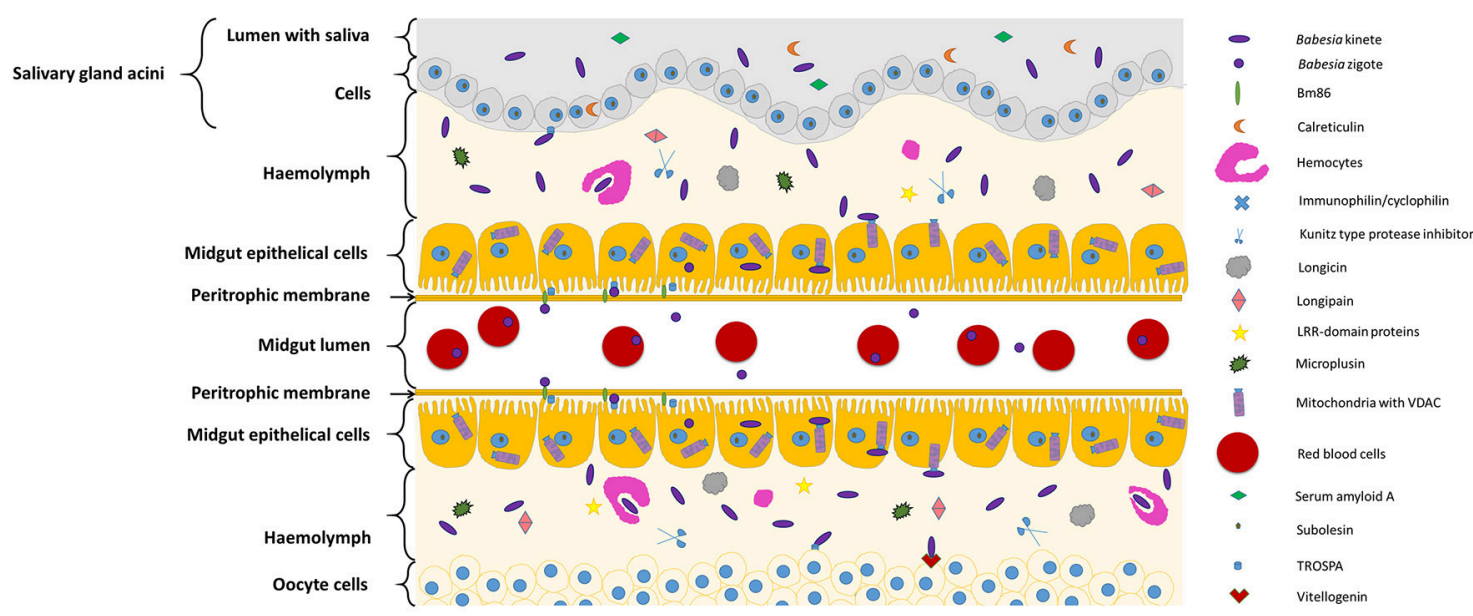

FIGURE 1 | Diagram representing tick molecules implicated in Babesia spp. acquisition and transmission by the vector. When ticks feed on Babesia-infected animals, parasites within red blood cellsreach and penetrate the tick midgut peritrophic membrane to invade the epithelial cells (in the figure center). Once these cells are infected, transcriptional factors, such as subolesin, can regulate protein expression in several cellular pathways, facilitating Babesia infection. In the microvilli of the midgut cells, parasite zygotes will probably interact with a tick glycoprotein (Bm86) and a tick receptor of the outer surface protein A (TROSPA). Inside the epithelial cells, mitochondria porins (VDAC) can bind to Babesia kinete proteins promoting plasminogen activation in the cell surface, allowing their passage to the haemolymph Once here, the haemocytes can phagocyte circulating parasites and the tick antimicrobial molecules such as, longicin, micropulsin, longipain, LRR-domain and Kunitz-type protease inhibitors are activated potentially reducing the infection in the vector. If the infectious parasites surpass these barriers of defense, they will be capable to spread across the tissues and invade ovaries (represented in the bottom of the figure) and SGs (represented in the top of the figure). In the ovary, the interaction of Babesia molecules with tick vitellogenin and TROSPA receptors may contribute for the occurrence of transovarial transmission; while in the SGs, Babesia interacts with TROSPA and calreticulin. 
TABLE 1 | Tick molecules interfering with Babesia spp. infection.

\begin{tabular}{|c|c|c|c|c|c|c|c|}
\hline \multirow[t]{2}{*}{ Protein name } & \multirow[t]{2}{*}{ Assigned function } & \multicolumn{4}{|c|}{ Proteins localization } & \multirow[t]{2}{*}{ Described effect in Babesia spp. infection } & \multirow[t]{2}{*}{ References } \\
\hline & & MD & HL & OV & SG & & \\
\hline $\begin{array}{l}\text { Mitochondrial } \\
\text { voltage-dependent } \\
\text { anion-selective channel } \\
\text { (BmVDAC) }\end{array}$ & $\begin{array}{l}\text { Cell metabolism and } \\
\text { apoptosis regulation }\end{array}$ & $x$ & & & & Enhance acquisition & $\begin{array}{l}\text { Rodríguez-Hernández et al., } \\
\text { 2012, } 2015\end{array}$ \\
\hline $\begin{array}{l}\text { Tick receptor of the } \\
\text { outer surface protein A } \\
\text { (TROSPA) }\end{array}$ & $\begin{array}{l}\text { Factor for tick gut } \\
\text { colonization }\end{array}$ & $x$ & & $x$ & $x$ & Enhance acquisition & $\begin{array}{l}\text { Antunes et al., 2012; Merino } \\
\text { et al., 2013; Urbanowicz et al., } \\
2016\end{array}$ \\
\hline Longicin & Defensin & $x$ & & & & Control acquisition and transovarial transmission & Tsuji et al., 2007 \\
\hline Microplusin & Antimicrobial peptide & $x$ & & & & & Antunes et al., 2012 \\
\hline Longipain & Cysteine protease & $x$ & & & & & Tsuji et al., 2008 \\
\hline $\begin{array}{l}\text { Leucine-rich repeat } \\
\text { domain-containing } \\
\text { proteins }\end{array}$ & $\begin{array}{l}\text { Component of the } \\
\text { innate immune system }\end{array}$ & $x$ & $x$ & $x$ & $x$ & Control infection & Maeda et al., 2015 \\
\hline $\begin{array}{l}\text { Kunitz-type protease } \\
\text { inhibitors }\end{array}$ & Blood coagulation & $x$ & & & $x$ & Enhance transovarial transmission & $\begin{array}{l}\text { Rachinsky et al., 2007; Bastos } \\
\text { et al., 2009; Antunes et al., } \\
2012\end{array}$ \\
\hline Bm86 & $\begin{array}{l}\text { Blood coagulation and } \\
\text { cell growth }\end{array}$ & $x$ & & $x$ & & Enhance acquisition & Bastos et al., 2010 \\
\hline Subolesin & $\begin{array}{l}\text { Transcriptional factor } \\
\text { involved in the immune } \\
\text { signaling pathways }\end{array}$ & $x$ & & & & Enhance acquisition & $\begin{array}{l}\text { Merino et al., 2011; de la } \\
\text { Fuente et al., } 2013\end{array}$ \\
\hline Immunophilin & $\begin{array}{l}\text { Protein folding, } \\
\text { trafficking and defense }\end{array}$ & & $x$ & & & Control transovarial transmission & $\begin{array}{l}\text { Rachinsky et al., 2007; Wang } \\
\text { and Heitman, } 2005\end{array}$ \\
\hline $\begin{array}{l}\text { Vitellogenin receptor } \\
(\text { VgR) }\end{array}$ & Vitellogenin uptake & & & $X$ & & Enhance transovarial transmission & Boldbaatar et al., 2008, 2010 \\
\hline Serum amyloid A & $\begin{array}{l}\text { Response to } \\
\text { inflammation }\end{array}$ & $x$ & & & & Enhance acquisition & Antunes et al., 2012 \\
\hline Calreticulin & $\begin{array}{l}\text { Protein folding and } \\
\text { signaling }\end{array}$ & $x$ & & $X$ & $x$ & Enhance acquisition. & Antunes et al., 2012 \\
\hline
\end{tabular}

MD, Midgut; HL, Haemolymph; OV, Ovaries; SG, Salivary Glands.

importance during Babesia-vector-host interactions and it seems likely that more molecules will emerge as key players in these vector-parasite networks in the near future.

Figure 1, Table 1 summarizes the so far identified tick molecules networking with Babesia spp. showing their localization and suggested interaction.

\section{CONCLUSIONS}

The major critical point for the development of vaccines is the identification of new targets. In this review, our objective was to gather relevant information about the tick molecules involved with Babesia parasite infections. During the last decade, several studies using "omics" and systems biology approaches have greatly improved our knowledge of the interactions taking place at the tick-pathogen interface. The Babesia-tick interactome is still neglected with scattered information, and only a few tick proteins have been shown to influence the acquisition, dissemination and transmission of the parasite. From this short list, subolesin, having a role in the tick innate immune response, stands out as a potential candidate antigen for a universal antivector vaccine. During Babesia infection, this molecule produced positive results, making it a candidate antigen for a transmissionblocking vaccine. Other proteins involved in Babesia acquisition, including the TROSPA receptor, are also promising candidates for a multi-antigenic vaccine. Some of these datasets were obtained through use of transcriptomic, proteomic, and systems biology approaches. These and future technologies will be fundamental to the improvement and development of new control strategies and more effective vaccines.

\section{AUTHOR CONTRIBUTIONS}

SA, JF, CR, and AD conducted the literature research and wrote the paper. SA and CR prepared the table and JC prepared the figure. All authors critically read and revised the manuscript.

\section{ACKNOWLEDGMENTS}

Authors would like to thank Sarah Bonnet for the valuable suggestions and comments to the present review and also Mark Gibson for the English revision. Fundação para a Ciência e Tecnologia (FCT) for funds to GHTM-UID/Multi/04413/2013 and project PTDC/CVT-EPI/4339/2012. 


\section{REFERENCES}

Almazán, C., Kocan, K. M., Bergman, D. K., Garcia-Garcia, J. C., Blouin, E. F., and de la Fuente, J. (2003). Identification of protective antigens for the control of Ixodes scapularis infestations using cDNA expression library immunization. Vaccine 21, 1492-1501. doi: 10.1016/S0264-410X(02)00683-7

Alzan, H. F., Lau, A. O., Knowles, D. P., Herndon, D. R., Ueti, M. W., Scoles, G. A., et al. (2016). Expression of 6-Cys gene superfamily defines Babesia bovis sexual stage development within Rhipicephalus microplus. PLoS ONE 11:e0163791. doi: 10.1371/journal.pone.0163791

Anatriello, E., Ribeiro, J. M. C., de Miranda-Santos, I. K. F., Brandao, L. G., Anderson, J. M., Valenzuela, J. G., et al. (2010). An insight into the sialotranscriptome of the brown dog tick, Rhipicephalus sanguineus. BMC Genomics 11:450. doi: 10.1186/1471-2164-11-450

Antunes, S., Galindo, R. C., Almazan, C., Rudenko, N., Golovchenko, M., Grubhoffer, L., et al. (2012). Functional genomics studies of Rhipicephalus (Boophilus) annulatus ticks in response to infection with the cattle protozoan parasite, Babesia bigemina. Int. J. Parasitol. 42, 187-195. doi: 10.1016/j.ijpara.2011.12.003

Antunes, S., Merino, O., Lerias, J., Domingues, N., Mosqueda, J., de la Fuente, J., et al. (2015). Artificial feeding of Rhipicephalus microplus female ticks with anti calreticulin serum do not influence tick and Babesia bigemina acquisition. Ticks Tick Borne Dis. 6, 47-55. doi: 10.1016/j.ttbdis.2014.0 9.003

Antunes, S., Merino, O., Mosqueda, J., Moreno-Cid, J. A., Bell-Sakyi, L., Fragkoudis, R., et al. (2014). Tick capillary feeding for the study of proteins involved in tick-pathogen interactions as potential antigens for the control of tick infestation and pathogen infection. Parasit. Vectors 7:42. doi: 10.1186/1756-3305-7-42

Bastos, R. G., Suarez, C. E., Laughery, J. M., Johnson, W. C., Ueti, M. W., and Knowles, D. P. (2013). Differential expression of three members of the multidomain adhesion CCp family in Babesia bigemina, Babesia bovis and Theileria equi. PLoS ONE 8:e67765. doi: 10.1371/journal.pone.00 67765

Bastos, R. G., Ueti, M. W., Guerrero, F. D., Knowles, D. P., and Scoles, G. A. (2009). Silencing of a putative immunophilin gene in the cattle tick Rhipicephalus (Boophilus) microplus increases the infection rate of Babesia bovis in larval progeny. Parasit. Vectors 2:57. doi: 10.1186/1756-3305-2-57

Bastos, R. G., Ueti, M. W., Knowles, D. P., and Scoles, G. A. (2010). The Rhipicephalus (Boophilus) microplus Bm86 gene plays a critical role in the fitness of ticks fed on cattle during acute Babesia bovis infection. Parasit. Vectors 3:111. doi: 10.1186/1756-3305-3-111

Bock, R., Jackson, L., De Vos, A., and Jorgensen, W. (2004). Babesiosis of cattle. Parasitology 129, S247-S269. doi: 10.1017/S0031182004005190

Boldbaatar, D., Battsetseg, B., Matsuo, T., Hatta, T., Umemiya-Shirafuji, R., Xuan, X., et al. (2008). Tick vitellogenin receptor reveals critical role in oocyte development and transovarial transmission of Babesia parasite. Biochem. Cell Biol. 86, 331-344. doi: 10.1139/O08-071

Boldbaatar, D., Umemiya-Shirafuji, R., Liao, M., Tanaka, T., Xuan, X. N., and Fujisaki, K. (2010). Multiple vitellogenins from the Haemaphysalis longicornis tick are crucial for ovarian development. J. Insect Physiol. 56, 1587-1598. doi: 10.1016/j.jinsphys.2010.05.019

Cen-Aguilar, J. F., Rodriguez-Vivas, R. I., Dominguez-Alpizar, J. L., and Wagner, G. G. (1998). Studies on the effect of infection by Babesia sp. on oviposition of Boophilus microplus engorged females naturally infected in the Mexican tropics. Vet. Parasitol. 78, 253-257. doi: 10.1016/S0304-4017(98)00 148-4

Chao, L. L., Liao, H. T., Ho, T. Y., and Shih, C. M. (2017). First detection and molecular identification of Babesia gibsoni from Rhipicephalus sanguineus ticks. Acta Trop. 166, 356-362. doi: 10.1016/j.actatropica.2016.09.022

Chauvin, A., Moreau, E., Bonnet, S., Plantard, O., and Malandrin, L. (2009). Babesia and its hosts: adaptation to long-lasting interactions as a way to achieve efficient transmission. Vet. Res. 40:37. doi: 10.1051/vetres/20 09020

Coleman, J. L., Gebbia, J. A., Piesman, J., Degen, J. L., Bugge, T. H., and Benach, J. L. (1997). Plasminogen is required for efficient dissemination of B. burgdorferi in ticks and for enhancement of spirochetemia in mice. Cell 89, 1111-1119. doi: 10.1016/S0092-8674(00)80298-6 de Castro, M. H., de Klerk, D., Pienaar, R., Latif, A. A., Rees, D. J. G., and Mans, B. J. (2016). De novo assembly and annotation of the salivary gland transcriptome of Rhipicephalus appendiculatus male and female ticks during blood feeding. Ticks Tick Borne Dis. 7, 536-548. doi: 10.1016/j.ttbdis.2016.0 1.014

de la Fuente, J., Moreno-Cid, J. A., Galindo, R. C., Almazan, C., Kocan, K. M., Merino, O., et al. (2013). Subolesin/Akirin vaccines for the control of arthropod vectors and vectorborne pathogens. Transbound. Emerg. Dis. 60, 172-178. doi: 10.1111/tbed.12146

de la Fuente, J., Villar, M., Cabezas-Cruz, A., Estrada-Pena, A., Ayllon, N., and Alberdi, P. (2016). Tick-host-pathogen interactions: conflict and cooperation. PLoS Pathog. 12:e1005488. doi: 10.1371/journal.ppat.1005488

de Rezende, J., Rangel, C. P., McIntosh, D., Silveira, J. A., Cunha, N. C., Ramos, C. A., et al. (2015). In vitro cultivation and cryopreservation of Babesia bigemina sporokinetes in hemocytes of Rhipicephalus microplus. Vet. Parasitol. 212, 400-403. doi: 10.1016/j.vetpar.2015.07.008

Esteves, E., Lara, F. A., Lorenzini, D. M., Costa, G. H., Fukuzawa, A. H., Pressinotti, L. N., et al. (2008). Cellular and molecular characterization of an embryonic cell line (BME26) from the tick Rhipicephalus (Boophilus) microplus. Insect Biochem. Mol. Biol. 38, 568-580. doi: 10.1016/j.ibmb.2008.0 1.006

Ferreira, C. A. S., Vaz, I. D., da Silva, S. S., Haag, K. L., Valenzuela, J. G., and Masuda, A. (2002). Cloning and partial characterization of a Boophilus microplus (Acari: Ixodidae) calreticulin. Exp. Parasitol. 101, 25-34. doi: 10.1016/S0014-4894(02)00032-2

Ferreira, V., Molina, M. C., Valck, C., Rojas, A., Aguilar, L., Ramirez, G., et al. (2004). Role of calreticulin from parasites in its interaction with vertebrate hosts. Mol. Immunol. 40, 1279-1291. doi: 10.1016/j.molimm.2003.11.018

Ferrolho, J., Antunes, S., Santos, A. S., Velez, R., Padre, L., Cabezas-Cruz, A., et al. (2016). Detection and phylogenetic characterization of Theileria spp. and Anaplasma marginale in Rhipicephalus bursa in Portugal. Ticks Tick Borne Dis. 7, 443-438. doi: 10.1016/j.ttbdis.2016.01.004

Florin-Christensen, M., and Schnittger, L. (2009). Piroplasmids and ticks: a longlasting intimate relationship. Front. Biosci. 14:3435. doi: 10.2741/3435

Fogaça, A. C., Lorenzini, D. M., Kaku, L. M., Esteves, E., Bulet, P. and Daffre, S. (2004). Cysteine-rich antimicrobial peptides of the cattle tick Boophilus microplus: isolation, structural characterization and tissue expression profile. Dev. Comp. Immunol. 28, 191-200. doi: 10.1016/j.dci.2003.0 8.001

Francischetti, I. M. B., Anderson, J. M., Manoukis, N., Pham, V. M., and Ribeiro, J. M. C. (2011). An insight into the sialotranscriptome and proteome of the coarse bontlegged tick, Hyalomma marginatum rufipes. J. Proteomics 74, 2892-2908. doi: 10.1016/j.jprot.2011.07.015

Francischetti, I. M., Mans, B. J., Meng, Z., Gudderra, N., Veenstra, T. D., Pham, V. M., et al. (2008). An insight into the sialome of the soft tick, Ornithodorus parkeri. Insect Biochem. Mol. Biol. 38, 1-21. doi: 10.1016/j.ibmb.2007.0 9.009

Galindo, R. C., Doncel-Perez, E., Zivkovic, Z., Naranjo, V., Gortazar, C. Mangold, A. J., et al. (2009). Tick subolesin is an ortholog of the akirins described in insects and vertebrates. Dev. Comp. Immunol. 33, 612-617. doi: 10.1016/j.dci.2008.11.002

Garcia, G. R., Gardinassi, L. G., Ribeiro, J. M., Anatriello, E., Ferreira, B. R., Moreira, H. N., et al. (2014). The sialotranscriptome of Amblyomma triste, Amblyomma parvum and Amblyomma cajennense ticks, uncovered by 454 based RNA-seq. Parasit. Vectors 7:430. doi: 10.1186/1756-3305-7-430

Ghosh, A. K., Coppens, I., Gårdsvoll, H., Ploug, M., and Jacobs-Lorena, M. (2011). Plasmodium ookinetes coopt mammalian plasminogen to invade the mosquito midgut. Proc. Natl. Acad. Sci. U.S.A. 108, 17153-17158. doi: 10.1073/pnas.1103657108

Gou, H., Guan, G., Liu, A., Ma, M., Chen, Z., Liu, Z., et al. (2013). Coevolutionary analyses of the relationships between piroplasmids and their hard tick hosts. Ecol. Evol. 3, 2985-2993. doi: 10.1002/ece3.685

Gough, J. M., and Kemp, D. H. (1993). Localization of a low abundance membrane protein $(\mathrm{Bm} 86)$ on the gut cells of the cattle tick Boophilus microplus by immunogold labeling. J. Parasitol. 79, 900-907. doi: 10.2307/3283728

Hajdusek, O., Sima, R., Ayllon, N., Jalovecka, M., Perner, J., de la Fuente, J., et al. (2013). Interaction of the tick immune system with transmitted pathogens. Front. Cell. Infect. Microbiol. 3:26. doi: 10.3389/fcimb.2013.00026 
Heekin, A. M., Guerrero, F. D., Bendele, K. G., Saldivar, L., Scoles, G. A., Dowd, S. E., et al. (2013). Gut transcriptome of replete adult female cattle ticks, Rhipicephalus (Boophilus) microplus, feeding upon a Babesia bovisinfected bovine host. Parasitol. Res. 112, 3075-3090. doi: 10.1007/s00436-013-3 482-4

Homer, M. J., Aguilar-Delfin, I., Telford, S. R., Krause, P. J., and Persing, D. H. (2000). Babesiosis. Clin. Microbiol. Rev. 13, 451-469. doi: 10.1128/CMR.13.3.451-469.2000

Inoue, N., Hanada, K., Tsuji, N., Igarashi, I., Nagasawa, H., Mikami, T., et al. (2001). Characterization of phagocytic hemocytes in Ornithodoros moubata (Acari: Ixodidae). J. Med. Entomol. 38, 514-519. doi: 10.1603/0022-2585-38.4.514

Jaworski, D. C., Simmen, F. A., Lamoreaux, W., Coons, L. B., Muller, M. T., and Needham, G. R. (1995). A secreted calreticulin protein in ixodid tick (Amblyomma americanum) saliva. J. Insect Physiol. 41, 369-375. doi: 10.1016/0022-1910(94)00107-R

Karim, S., Singh, P., and Ribeiro, J. M. C. (2011). A Deep insight into the Sialotranscriptome of the gulf coast tick, Amblyomma maculatum. PLoS ONE 6:e28525. doi: 10.1371/journal.pone.0028525

Kim, T. K., Guaratini Ibelli, A. M., and Mulenga, A. (2015). Amblyomma americanum tick calreticulin binds $\mathrm{C} 1 \mathrm{q}$ but does not inhibit activation of the classical complement cascade. Ticks Tick Borne Dis. 6, 91-101. doi: 10.1016/j.ttbdis.2014.10.002

Konnai, S., Yamada, S., Imamura, S., Nishikado, H., Githaka, N., Ito, T., et al. (2012). Identification of TROSPA homologue in Ixodes persulcatus Schulze, the specific vector for human Lyme borreliosis in Japan. Ticks Tick Borne Dis. 3, 75-77. doi: 10.1016/j.ttbdis.2012.02.001

Kopacek, P., Hajdusek, O., Buresova, V., and Daffre, S. (2010). Tick innate immunity. Invertebr. Immun. 708, 137-162. doi: 10.1007/978-1-4419-8059-5_8

Kotsyfakis, M., Kopácek, P., Franta, Z., Pedra, J. H., and Ribeiro, J. M. (2015). Deep sequencing analysis of the Ixodes ricinus haemocytome. PLoS Negl. Trop. Dis. 9:e0003754. doi: 10.1371/journal.pntd.00 03754

Lack, J. B., Reichard, M. V., and Van Den Bussche, R. A. (2012). Phylogeny and evolution of the Piroplasmida as inferred from 18S rRNA sequences. Int. J. Parasitol. 42, 353-363. doi: 10.1016/j.ijpara.2012.02.005

Leiby, D. A. (2006). Babesiosis and blood transfusion: flying under the radar. Vox Sang. 90, 157-165. doi: 10.1111/j.1423-0410.2006.00740.x

Maeda, H., Hatta, T., Alim, M. A., Tsubokawa, D., Mikami, F., Kusakisako, K., et al. (2017). Initial development of Babesia ovata in the tick midgut. Vet. Parasitol. 233, 39-42. doi: 10.1016/j.vetpar.2016.11.020

Maeda, H., Kurisu, K., Miyata, T., Kusakisako, K., Galay, R. L., Rio, T. M., et al. (2015). Identification of the Babesia-responsive leucine-rich repeat domaincontaining protein from the hard tick Haemaphysalis longicornis. Parasitol. Res. 114, 1793-1802. doi: 10.1007/s00436-015-4365-7

Merino, O., Almazan, C., Canales, M., Villar, M., Moreno-Cid, J. A., Galindo, R. C., et al. (2011). Targeting the tick protective antigen subolesin reduces vector infestations and pathogen infection by Anaplasma marginale and Babesia bigemina. Vaccine 29, 8575-8579. doi: 10.1016/j.vaccine.2011.0 9.023

Merino, O., Antunes, S., Mosqueda, J., Moreno-Cid, J. A., Perez de la Lastra, J. M., Rosario-Cruz, R., et al. (2013). Vaccination with proteins involved in tick-pathogen interactions reduces vector infestations and pathogen infection. Vaccine 31, 5889-5896. doi: 10.1016/j.vaccine.2013.09.037

Moreno-Cid, J. A., Perez de la Lastra, J. M., Villar, M., Jimenez, M., Pinal, R., Estrada-Pena, A., et al. (2013). Control of multiple arthropod vector infestations with subolesin/akirin vaccines. Vaccine 31, 1187-1196. doi: 10.1016/j.vaccine.2012.12.073

Mosqueda, J., Falcon, A., Antonio Alvarez, J., Alberto Ramos, J., OropezaHernandez, L. F., and Figueroa, J. V. (2004). Babesia bigemina sexual stages are induced in vitro and are specifically recognized by antibodies in the midgut of infected Boophilus microplus ticks. Int. J. Parasitol. 34, 1229-1236. doi: 10.1016/j.ijpara.2004.07.003

Ord, R. L., and Lobo, C. A. (2015). Human babesiosis: pathogens, prevalence, diagnosis and treatment. Curr. Clin. Microbiol. Rep. 2, 173-181. doi: $10.1007 / \mathrm{s} 40588-015-0025-\mathrm{Z}$

Pal, U., Li, X., Wang, T., Montgomery, R. R., Ramamoorthi, N., deSilva, A. M., et al. (2004). TROSPA, an Ixodes scapularis receptor for Borrelia burgdorferi. Cell 119, 457-468. doi: 10.1016/j.cell.2004.10.027
Perner, J., Sobotka, R., Sima, R., Konvickova, J., Sojka, D., Oliveira, P. L., et al. (2016). Acquisition of exogenous haem is essential for tick reproduction. Elife 5:e12318. doi: 10.7554/eLife.12318

Rachinsky, A., Guerrero, F. D., and Scoles, G. A. (2007). Differential protein expression in ovaries of uninfected and Babesia-infected southern cattle ticks, Rhipicephalus (Boophilus) microplus. Insect Biochem. Mol. Biol. 37, 1291-1308. doi: 10.1016/j.ibmb.2007.0 8.001

Ranjbar-Bahadori, S., Eckert, B., Omidian, Z., Shirazi, N. S., and Shayan, P. (2012). Babesia ovis as the main causative agent of sheep babesiosis in Iran. Parasitol. Res. 110, 1531-1536. doi: 10.1007/s00436-011-2658-Z

Ribeiro, J. M., Anderson, J. M., Manoukis, N. C., Meng, Z., and Francischetti, I. M. (2011). A further insight into the sialome of the tropical bont tick, Amblyomma variegatum. BMC Genomics 12:136. doi: 10.1186/1471-2164-1 2-136

Rodríguez-Hernández, E., Mosqueda, J., Alvarez-Sánchez, M. E., Neri, A. F., Mendoza-Hernández, G., and Camacho-Nuez, M. (2012). The identification of a VDAC-like protein involved in the interaction of Babesia bigemina sexual stages with Rhipicephalus microplus midgut cells. Vet. Parasitol. 187, 538-541. doi: 10.1016/j.vetpar.2012.01.028

Rodríguez-Hernández, E., Mosqueda, J., León-Ávila, G., Castañeda-Ortiz, E. J., Álvarez-Sánchez, M. E., Camacho, A. D., et al. (2015). BmVDAC upregulation in the midgut of Rhipicephalus microplus, during infection with Babesia bigemina. Vet. Parasitol. 212, 368-374. doi: 10.1016/j.vetpar.2015.06.016

Rodríguez-Mallon, A. (2016). Developing Anti-tick Vaccines. Methods Mol. Biol. 1404, 243-259. doi: 10.1007/978-1-4939-3389-1_17

Rodríguez-Mallon, A., Bechara, G., Zacarias, R., Benavides-Ortiz, E., SotoRivas, J., Gómez-Ramírez, A., et al. (2013). Inhibition of Ehrlichia canis and Babesia canis transmission among ticks fed together on dogs vaccinated with Bm86 antigen. Open J. Anim. Sci. 3:24. doi: 10.4236/ojas.2013.3 $3 \mathrm{~A} 004$

Rudenko, N., Golovchenko, M., Edwards, M. J., and Grubhoffer, L. (2005). Differential expression of Ixodes ricinus tick genes induced by blood feeding or Borrelia burgdorferi infection. J. Med. Entomol. 42, 36-41. doi: $10.1093 /$ jmedent/42.1.36

Sasaki, S. D., and Tanaka, A. S. (2008). rBmTI-6, a Kunitz-BPTI domain protease inhibitor from the tick Boophilus microplus, its cloning, expression and biochemical characterization. Vet. Parasitol. 155, 133-141. doi: 10.1016/j.vetpar.2008.03.031

Schnittger, L., Rodriguez, A. E., Florin-Christensen, M., and Morrison, D. A. (2012). Babesia: a world emerging. Infect. Genet. Evol. 12, 1788-1809. doi: 10.1016/j.meegid.2012.07.004

Shayan, P., Hooshmand, E., Rahbari, S., and Nabian, S. (2007). Determination of Rhipicephalus spp. as vectors for Babesia ovis in Iran. Parasitol. Res. 101, 1029-1033. doi: 10.1007/s00436-007-0581-0

Solano-Gallego, L., Sainz, Á., Roura, X., Estrada-Peña, A., and Miró, G. (2016). A review of canine babesiosis: the European perspective. Parasit. Vectors 9, 336. doi: 10.1186/s13071-016-1596-0

Sonenshine, D. E., and Hynes, W. L. (2008). Molecular characterization and related aspects of the innate immune response in ticks. Front. Biosci. 13:3209. doi: $10.2741 / 3209$

Sonenshine, D. E., and Michael Roe, R. (2014). Biology of Ticks, 2nd Edn. New York, NY: Oxford University Press.

Sultana, H., Patel, U., Sonenshine, D. E., and Neelakanta, G. (2015) Identification and comparative analysis of subolesin/akirin ortholog from Ornithodoros turicata ticks. Parasit. Vectors 8:132. doi: 10.1186/s13071-015-0 749-x

Tonk, M., Cabezas-Cruz, A., Valdés, J. J., Rego, R. O., Grubhoffer, L., Estrada-Peña, A., et al. (2015). Ixodes ricinus defensins attack distantlyrelated pathogens. Dev. Comp. Immunol. 53, 358-365. doi: 10.1016/j.dci.2015. 08.001

Tsuji, N., Battsetseg, B., Boldbaatar, D., Miyoshi, T., Xuan, X., Oliver, J. H. Jr., et al. (2007). Babesial vector tick defensin against Babesia sp. parasites. Infect. Immun. 75, 3633-3640. doi: 10.1128/IAI.00256-07

Tsuji, N., Miyoshi, T., Battsetseg, B., Matsuo, T., Xuan, X., and Fujisaki, K. (2008). A cysteine protease is critical for Babesia spp. transmission in Haemaphysalis ticks. PLoS Pathog. 4:e1000062. doi: 10.1371/journal.ppat.10 00062 
Urbanowicz, A., Lewandowski, D., Szpotkowski, K., and Figlerowicz, M. (2016). Tick receptor for outer surface protein A from Ixodes ricinus-the first intrinsically disordered protein involved in vector-microbe recognition. Sci. Rep. 6:25205. doi: 10.1038/ srep25205

Villar, M., Ayllon, N., Alberdi, P., Moreno, A., Moreno, M., Tobes, R., et al. (2015). Integrated metabolomics, transcriptomics and proteomics identifies metabolic pathways affected by Anaplasma phagocytophilum Infection in tick cells. Mol. Cell. Proteomics 14, 3154-3172. doi: 10.1074/mcp.M115.0 51938

Wang, P., and Heitman, J. (2005). The cyclophilins. Genome Biol. 6:226. doi: $10.1186 / \mathrm{gb}-2005-6-7-226$

Young, M. J., Bay, D. C., Hausner, G., and Court, D. A. (2007). The evolutionary history of mitochondrial porins. BMC Evol. Biol. 7:31. doi: 10.1186/1471-2148-7-31

Yu, X., Gong, H., Zhou, Y., Zhang, H., Cao, J., and Zhou, J. (2015). Differential sialotranscriptomes of unfed and fed Rhipicephalus haemaphysaloides, with particular regard to differentially expressed genes of cysteine proteases. Parasit. Vectors 8:597. doi: 10.1186/s13071-015-1213-7

Zivkovic, Z., Torina, A., Mitra, R., Alongi, A., Scimeca, S., Kocan, K. M., et al. (2010). Subolesin expression in response to pathogen infection in ticks. BMC Immunol. 11:7. doi: 10.1186/1471-2172-11-7

Conflict of Interest Statement: The authors declare that the research was conducted in the absence of any commercial or financial relationships that could be construed as a potential conflict of interest.

Copyright (c) 2017 Antunes, Rosa, Couto, Ferrolho and Domingos. This is an openaccess article distributed under the terms of the Creative Commons Attribution License (CC BY). The use, distribution or reproduction in other forums is permitted, provided the original author(s) or licensor are credited and that the original publication in this journal is cited, in accordance with accepted academic practice. No use, distribution or reproduction is permitted which does not comply with these terms. 